\title{
Continuous Non-Invasive Cardiac Output: Myth or Reality
}

\author{
João Manoel Rossi Neto ${ }^{(1)}$ \\ Instituto Dante Pazzanese de Cardiologia, São Paulo, SP - Brazil \\ Grupo Fleury, São Paulo, SP - Brazil \\ Short Editorial related to the article: Test-Retest Reliability of Non-Invasive Cardiac Output Measurement during Exercise in Healthy Volunteers \\ in Daily Clinical Routine
}

Cardiac output (CO) is an important cardiovascular system function parameter. Changes in cardiac function are commonly observed as a response to physical training and pharmacological interventions. ${ }^{1}$ Unfortunately, the methods for assessing $\mathrm{CO}$ are invasive, leading to well-known complications and considered inconvenient in daily practice. ${ }^{2}$ For this reason, the search for new noninvasive methods that can accurately detect $\mathrm{CO}$ at rest, at physical exertion or as a response to a clinical intervention has become desirable in academic and non-academic circles. The ideal method for measuring $\mathrm{CO}$ at rest and during exercise should be noninvasive, safe, reproducible and inexpensive. ${ }^{3}$

The Cardiopulmonary Exercise Testing (CPT) is recommended in the evaluation of cardiorespiratory fitness and exercise tolerance in athletes, the general population and in patients. ${ }^{4}$ Briefly, CO and systolic volume can be estimated during CPT through measured $\mathrm{VO}_{2} .{ }^{5}$ In 2001 , Williams et al. ${ }^{6}$ were the first ones to integrate CPT with non-invasive measures of $\mathrm{CO}$ using rebreathing $(\mathrm{RB})$ of carbon dioxide, but the technique was quickly abandoned due to its difficulty and inaccuracy. Another non-invasive method is thoracic electrical bioimpedance (TEB), first described in 1966 by Kubicek et al., ${ }^{7}$ which measures thoracic resistance as a result of changes in blood velocity during the cardiac cycle and uses an algorithm to calculate the CO.

Another promising technique is based on thoracic bioreactance (TB) (NICOM ${ }^{\mathrm{TM}}$, Cheetah Medical Inc., Wilmington, DE), which analyzes the variations in beat-to-beat tension after a high-frequency transthoracic current is applied. This device records the electric current phase in the thorax. The systolic volume is directly proportional to the phase displacement. ${ }^{8}$ Despite some controversial studies, this technique seemed to be more reliable. ${ }^{8-10}$ It is worth mentioning that the $\mathrm{CO}$ measurement is simple to perform and does not require patient cooperation, both at rest and at the exercise peak. It should be noted that some conditions, such as significant pleural effusion, have a negative impact on the accuracy of this method. ${ }^{11}$

In a meta-analysis, the percentage errors for $\mathrm{CO}$ monitoring devices were $42 \%$ for TEB and TB, $40 \%$ for RB of carbon dioxide and $62 \%$ for the methods of pulse wave analysis. ${ }^{12}$

\section{Keywords}

Cardiac Ouput; Electric; Impedance; Pharmacological; Interventions; Breathing Exercise

Mailing Address: João Manoel Rossi Neto •

Instituto Dante Pazzanese de Cardiologia - Av. Dante Pazzanese,

500 - Prédio dos Ambulatórios - Setor de Transplante de Coração.

Postal Code 04012-909, São Paulo, SP - Brazil

E-mail: jmrossi@sti.com.br

DOI: 10.5935/abc.20190163
The most recent meta-analysis that evaluated adult and pediatric patients in different clinical situations (mostly in the hospital setting), it was demonstrated that TEB accuracy showed high heterogeneity between the studies and that the mean percentage error grouped in all the subgroups was above the acceptable $30 \%$. Therefore, TEB could not replace thermodilution and transthoracic echocardiography for the measurement of absolute $\mathrm{CO}$ values. ${ }^{13}$

Okwose et al. ${ }^{14}$ showed that the RB of an inert gas and TB methods had acceptable levels of agreement to estimate the $\mathrm{CO}$ at higher degrees of metabolic demand during a CPT. However, they concluded they could not be used interchangeably because of the great disparity in results at rest and in low-to-moderate intensity exercises. Unlike this study, Torto et al. ${ }^{15}$ showed that cardio-impedance could be less ideal for supramaximal exercise intensities.

In this issue, Coll et al. ${ }^{16}$ evaluated the test-retest reliability of $\mathrm{CO}$ and cardiac work during $\mathrm{CPT}$ by $\mathrm{TB}$ in healthy adults under routine clinical conditions in an uncontrolled environment.

They concluded that, according to the findings, there is an obstacle to the clinical use of TB in healthy individuals whereas outliers are not identified $(32 \%$ of the initial sample). That is, under routine clinical conditions, almost one-third of the patients showed measurement errors and, according to the authors, these outliers were probably due to an underlying technical reason; thus, further improvements in TB are required, such as regarding the use and the quality of the electrodes. This study contested the results of the study by Jones et al., ${ }^{11}$ which had demonstrated that TB could be viable under strict control conditions and in the research environment.

The results of the studies published to date showed that even in situations of in-hospital use and controlled environment (anesthesia, intensive care and even outpatient clinics) in which patients were at rest, noninvasive monitoring of $\mathrm{CO}$ showed great variability between the non-invasive methods and frequently showed unacceptable errors in relation to procedures considered as "gold standard", such as thermodilution. In an uncontrolled exercise scenario, both for the diagnosis of diseases and for the improvement of athlete conditioning, the non-invasive methods for $\mathrm{CO}$ monitoring seem to be more of a myth than a reality at present, when compared to the standard methods for calculating the $\mathrm{CO}$.

Further studies are needed to determine $\mathrm{CO}$ through noninvasive methods at rest and during exercise. Our hope is that in the near future, and with the progress in technological development, the non-invasive monitoring of $\mathrm{CO}$ can be used in controlled and uncontrolled environments, in addition to the current perioperative scenario. 


\section{Short Editorial}

\section{References}

1. Coats AJ, Adamopoulos S, Radaelli A, McCance A, Meyer TE, Bernardi L, et al. Controlled trial of physical training in chronic heart failure. Exercise performance, hemodynamics, ventilation, and autonomic function. Circulation. 1992;85(6):2119-31.

2. Cannesson M, Pestel G, Ricks C, Hoeft A, Perel A. Hemodynamic monitoring and management in patients undergoing high risk surgery: a survey among North American and European anesthesiologists. Crit Care. 2011;15(4):R197.

3. Vignati C, Cattadori G. Measuring Cardiac Output during Cardiopulmonary Exercise Testing. Ann Am Thorac Soc. 2017;14(Suppl1):S48-52.

4. Balady GJ, Arena R, Sietsema K, Myers J, Coke L, Fletcher GF, etal. Clinician's Guide to cardiopulmonary exercise testing in adults: a scientific statement from the American Heart Association. Circulation. 2010;122(2):191-225.

5. Stringer WW, Hansen JE, Wasserman K. Cardiac output estimated noninvasively from oxygen uptake during exercise. J Appl Physiol. 1997;82(3):908-12.

6. Williams SG, Cooke GA, Wright DJ, Parsons WJ, Riley RL, Marshall P, et al. Peak exercise cardiac power output; a direct indicator of cardiac function strongly predictive of prognosis in chronic heart failure. Eur Heart J. 2001;22(16):1496-503.

7. Kubicek WG, Karnegis JN, Patterson RP, Witsoe DA, Mattson RH. Development and evaluation of an impedance cardiac output system. Aerosp Med. 1966;37(12):1208-12.

8. Keren H, Burkhoff D, Squara P. Evaluation of a noninvasive continuous cardiac output monitoring system based on thoracic bioreactance. Am J Physiol Heart Circ Physiol. 2007;293(1):H583-589.
9. Raval NY, Squara P, Cleman M, Yalamanchili K, Winklmaier M, Burkhoff D. Multicenter evaluation of noninvasive cardiac output measurement by bioreactance technique. J Clin Monit Comput. 2008;22(2):113-9.

10. Rich JD, Archer SL, Rich S. Noninvasive cardiac output measurements in patients with pulmonary hypertension. Eur Respir J. 2013;42(1):125-33.

11. Jones TW, Houghton D, Cassidy S, MacGowan GA, Trenell MI, Jakovljevic DG. Bioreactance is a reliable method for estimating cardiac output at rest and during exercise. Br J Anaesth. 2015;115(3):386-91.

12. Joosten A, Desebbe O, Suehiro K, Murphy LS-L, Essiet M, Alexander B, et al. Accuracy and precision of non-invasive cardiac output monitoring devices in perioperative medicine: a systematic review and meta-analysist. $\mathrm{Br}$ J Anaesth. 2017;118(3):298-310.

13. Sanders M, Servaas S, Slagt C. Accuracy and precision of non-invasive cardiac output monitoring by electrical cardiometry: a systematic review and metaanalysis. J Clin Monit Comput. 2019 Jun 7 [Epub ahead of print]

14. Okwose NC, Chowdhury S, Houghton D, Trenell MI, Eggett C, Bates M, et al. Comparison of cardiac output estimates by bioreactance and inert gas rebreathing methods during cardiopulmonary exercise testing. Clin Physiol Funct Imaging. 2018;38(3):483-90.

15. del Torto A, Skattebo Ø, Hallén J, Capelli C. Cardiac output with modified cardio-impedance against inert gas rebreathing during sub-maximal and maximal cycling exercise in healthy and fit subjects. Eur J Appl Physiol. 2019;119(1):163-70.

16. Cool MT. Confiabilidade Teste-Reteste de Medição Não-Invasiva de Débito Cardíaco durante Exercício em Voluntários Saudáveis sob Condições Clínicas de Rotina. Arq Bras Cardiol. 2019; 113(2):231-239. 